\title{
Increasing childhood vaccination coverage of the refugee and migrant population in Greece through the European programme PHILOS, April 2017 to April 2018
}

Kassiani Mellou' ${ }^{1}$, Chrysovalantis Silvestros ${ }^{1}$, Eirini Saranti-Papasaranti ${ }^{1}$, Athanasios Koustenis ${ }^{1}$, loanna D. Pavlopoulou ${ }^{2}$, Theano Georgakopoulou ${ }^{1}$, Chryssoula Botsi ${ }^{1}$, Agapios Terzidis ${ }^{1}$

1. Hellenic Centre for Disease Control and Prevention, Athens, Greece

2. National and Kapodistrian University of Athens, Faculty of Nursing, 'P \& A Kyriakou' Children's Hospital, Athens, Greece

Correspondence: Kassiani Mellou (k.mellou@keelpno.gr)

Citation style for this article:

Mellou Kassiani, Silvestros Chrysovalantis, Saranti-Papasaranti Eirini, Koustenis Athanasios, Pavlopoulou loanna D., Georgakopoulou Theano, Botsi Chryssoula, Terzidis Agapios. Increasing childhood vaccination coverage of the refugee and migrant population in Greece through the European programme PHILOS, April 2017 to April 2018. Euro Surveill. 2019;24(27):pii=1800326. https://doi.org/10.2807/1560-7917.ES.2019.24.27.1800326

Article submitted on 19 Jun 2018 / accepted on 15 Jan 2019 / published on 04 July 2019

After the 2016 Balkan route border closures, vaccination of refugee children in Greece was mainly performed by non-governmental organisations. Activities varied between camps, resulting in heterogeneity of vaccination coverage (VC). In April 2017, the European programme 'PHILOS - Emergency health response to refugee crisis' took over vaccination coordination. Interventions were planned for the first time for refugee children in the community and unaccompanied minors at safe zones. From April 2017-April 2018, 57,615 vaccinations were performed against measlesmumps-rubella (MMR) $(21,031)$, diphtheria-tetanuspertussis (7,341), poliomyelitis (7,652), pneumococcal disease $(5,938)$, Haemophilus influenzae type b $(7,179)$ and hepatitis $B(8,474)$. In April 2018 , the vaccination status of children at camps (reception and identification centres and community facilities such as hostels/ hotels were excluded) was recorded and VC for each disease, stratified by dose, nationality and camp size, was calculated. More than $80 \%$ of the children received the first MMR dose, with VC dropping to $45 \%$ for the second dose. For all other vaccines, VC was $<50 \%$ for the first dose in children aged $0-4$ years and $<25 \%$ for the second dose. Despite challenges, PHILOS improved planning and monitoring of vaccination activities; however, further efforts towards improving $V C$ in refugee children are needed.

\section{Background}

In 2015, during the refugee crisis, over one million refugees and migrants journeyed across the Mediterranean Sea to Europe; in 2016 and 2017, a further 535,054 people arrived in Europe through the same route [1].

Greece is one of the major entry points of Europe. After the Balkan route border closures in 2016, thousands of refugees who entered Greece were not able to proceed towards their intended country of refuge and had to remain in Greece [2]. In 2016, 2017 and 2018 (January to
April), 173,450, 29,718 and 8,362 people, respectively, arrived at Greece's north-eastern Aegean Islands, with children < 15 years of age accounting for $38 \%$ of the total population [1]. In 2016, the Hellenic Immunisation Advisory Committee recommended vaccination against the following priority diseases for these newly arrived children: measles, mumps and rubella for children 1-14 years old and diphtheria, tetanus, pertussis, poliomyelitis, pneumococcal disease, Haemophilus influenzae type $b$ and hepatitis B for children 2 months -4 years old [3].

Until March 2017, vaccination of refugee children was mainly performed by non-governmental organisations (NGOs) under the coordination of the Greek Ministry of Health $(\mathrm{MoH})$. Vaccination activities varied by camp and not all camps were consistently covered by an NGO [4]. Moreover, the vaccination needs of the population living in the community (hostels, hotels, apartments, etc.) or 'safe zones' for unaccompanied minors, were not addressed in this phase. This lack of harmonisation of vaccination practices and the resulting heterogeneity of vaccination coverage (VC) was a public health concern.

Therefore, in April 2017 it was decided that the programme 'PHILOS - Emergency health response to refugee crisis' would take over the coordination of vaccination of refugee children in Greece. PHILOS was a programme of the Greek $\mathrm{MoH}$, implemented by the Hellenic Centre for Disease Control and Prevention (HCDCP) and funded by the Asylum, Migration and Integration Fund (AMIF) of the European Union's Directorate-General for Migration and Home Affairs. All activities were implemented under the supervision of the General Directorate of Public Health of the $\mathrm{MoH}$.

Here we present the activities of the PHILOS programme from April 2017-April 2018 and the results of 
TABLE 1

Demographic characteristics of refugee children at 25 mainland camps, Greece, April $2018(\mathrm{n}=3,786)$

\begin{tabular}{|c|c|c|c|}
\hline \multirow{2}{*}{\multicolumn{2}{|c|}{ Characteristics }} & \multicolumn{2}{|c|}{ Children } \\
\hline & & $n$ & $\%$ \\
\hline \multirow{3}{*}{ Sex } & Male & 2,002 & 52.9 \\
\hline & Female & 1,720 & 45.4 \\
\hline & Unknown & 64 & 1.7 \\
\hline \multirow{3}{*}{ Age group (years) } & $<1$ & 285 & 7.5 \\
\hline & $1-4$ & 1,224 & 32.3 \\
\hline & $5-14$ & 2,277 & 60.2 \\
\hline \multirow{5}{*}{ Nationality } & Syria & 1,591 & 42.0 \\
\hline & Iraq & 1,066 & 28.2 \\
\hline & Afghanistan & 749 & 19.8 \\
\hline & Other $^{\mathrm{a}}$ & 375 & 9.9 \\
\hline & Unknown & 5 & 0.1 \\
\hline
\end{tabular}

a There were 19 different nationalities recorded for the 375 children in the category of 'Other'.

the concluding assessment of VC in April 2018 of refugee children in Greece, by disease, as well as the challenges faced in the programme's implementation.

In this manuscript, we refer to refugees, asylum seekers and newly arrived migrants as refugees.

\section{Setting}

In recent years, refugees have entered Greece mainly through the north-eastern Aegean Islands. They are then placed at RICs (each island has one RIC) and are offered medical assessment and medical care, if needed. Depending on their asylum or vulnerability status, most people are then transferred to accommodation camps on the mainland, where they stay for a more extended period until they are finally hosted at hostels, hotels, apartments or other community facilities under the initiatives of the United Nations High Commissioner for Refugees (UNHCR) and other European Civil Protection and Humanitarian Aid Operations (ECHO) partners.

Unaccompanied children are initially placed at specially designed areas inside camps and RICs called 'safe zones', where they stay for a short period of time before they are transferred to community facilities.

\section{Vaccination activities at camps and reception and identification centres}

The PHILOS programme set up standard operating procedures (SOPs) regarding vaccination practices at camps and RICs. Each NGO had to inform the PHILOS team about planned vaccination activities and had to request permission from the $\mathrm{MoH}$ to proceed with vaccinations. From April 2017 to April 2018, Red Cross, Praksis, Doctors Without Borders (MSF) and Doctors of the World (MdM) supported vaccination at camps, alongside the 'Health for All' programme of the University of Athens [5]. Camps not covered by an NGO were assigned to PHILOS mobile unit teams and all interventions were organised with the cooperation of the Ministry of Migration Policy.

Before each vaccination intervention, assessment of vaccination needs was required. To overcome the challenges posed by the mobility of the population and the heterogeneity of previously implemented interventions, PHILOS personnel visited families door-to-door and actively recorded the vaccination status of all children 0-14 years of age using a standardised form, within 2 weeks of each vaccination intervention. The resulting data were deposited in a specially designed database and sent to the HCDCP, in accordance with Greece's legal framework for sensitive data protection.

All refugees were informed that they could opt-out of sharing their vaccination history or having their children vaccinated; however, written informed consent was not required given the practical limitations in the field.

The recorded information included: (i) a list of all the children 0-14 years of age hosted at each camp and their demographic characteristics (age, sex, nationality), (ii) each child's exact place of residence (container/ isobox) inside the camp or other information needed to locate them in future for vaccination, (iii) whether a child already had the World Health Organization (WHO) booklet or other type of vaccine documentation, (iv) any vaccines that a child had already received and (v) if a child had never been vaccinated or whose vaccination status was unknown. Collected data were used to establish the needs of refugee children at each individual camp, as well as at all of the camps as a whole, for better coordination of interventions.

While conducting the door-to-door household survey, personnel also informed the refugees of the planned vaccinations, their importance and how they would benefit the children. Whenever possible, the surveys were conducted with the support of cultural mediators to address possible queries from the population. Personnel also advised parents/guardians to keep their children's vaccine records for future reference and informed them of the importance of these documents for the children's registration at schools. Written information was also provided in English, Farsi, Urdu and Arabic.

A medical and a managerial coordinator were appointed for each intervention, in accordance with Greek law, which states that vaccination can only be performed in the presence of a medical doctor, preferably a paediatrician.

After the end of each intervention, vaccination teams reported the number of vaccinations performed to the HCDCP. Challenges encountered during interventions were also reported. All data were recorded in a common database. 
TABLE 2

Vaccination coverage ${ }^{\mathrm{a}}$ of refugee children at 25 mainland camps, Greece, April 2018

\begin{tabular}{|c|c|c|c|}
\hline Disease & Vaccine doses & $\begin{array}{l}\text { Number of vaccinated children/total number of children } \\
\text { recorded }\end{array}$ & $\%$ \\
\hline \multirow{2}{*}{ MMR } & First & $2,843 / 3,501$ & 81.2 \\
\hline & Second & $1,575 / 3,501$ & 45.0 \\
\hline \multirow{2}{*}{ DTP } & First & $699 / 1,509$ & 46.3 \\
\hline & Second & $369 / 1,509$ & 24.5 \\
\hline \multirow{2}{*}{ Poliomyelitis } & First & $704 / 1,509$ & 46.7 \\
\hline & Second & $370 / 1,509$ & 24.5 \\
\hline \multirow{2}{*}{ Pneumococcal disease } & First & $750 / 1,509$ & 49.7 \\
\hline & Second & $267 / 1,509$ & 17.7 \\
\hline \multirow{2}{*}{ Haemophilus influenzae type b } & First & $697 / 1,509$ & 46.2 \\
\hline & Second & $370 / 1,509$ & 24.5 \\
\hline \multirow{2}{*}{ Hepatitis B } & First & $733 / 1,509$ & 48.6 \\
\hline & Second & $372 / 1,509$ & 24.7 \\
\hline
\end{tabular}

DTP: Diphtheria-tetanus-pertussis; MMR: measles-mumps-rubella.

a The National Immunisation Advisory Committee in Greece recommends vaccination against MMR for children 1-14 years of age ( $=3,501)$ and against diphtheria-tetanus-pertussis, poliomyelitis, pneumococcal disease, Haemophilus influenzae type b and hepatitis B for children $0-4$ years of age $(n=1,509)$. Vaccination campaigns followed the aforementioned recommendations; thus, vaccination coverage for each disease is presented for the respective age group.

Interventions were also organised at safe zones to accommodate unaccompanied minors, after permission was granted by the Ministry of Migration Policy to organise such an intervention and to contact unaccompanied minors. The Ministry of Migration Policy informed the district attorneys that act as the legal guardians of unaccompanied minors in Greece about the interventions and their scope.

\section{Planning vaccination activities for refugee children living in the community}

As refugees were increasingly housed in hostels, hotels and apartments under the UNHCR initiatives, it was difficult to capture VC and needs. Therefore, a meeting with the UNHCR and their associated partner NGOs was organised to assess the VC of the refugee children living in the community and identify opportunities for better vaccination coordination. The NGO representatives at the meeting indicated that the children's VC was low and that the majority of children in their premises were unvaccinated for most of the diseases included in the Greek National Childhood Immunisation Programme (NCIP). It was agreed that the HCDCP and the NGOs' representatives would collaborate closely to address this.

For this reason, each of Greece's seven health regions designated at least two community healthcare centres as vaccination centres that would cover the needs of the refugee child population living in the community. Vaccines and vaccination booklets were sent to the vaccination centres, and NGOs booked the appointments and trained the refugees on how to access the healthcare system.

\section{Vaccination campaigns}

Vaccinations at camps and RICs were delivered through mass vaccination campaigns. The number of campaigns held at each camp depended on the size of the hosted population, the amount of new arrivals and the site's resources. At minimum, camps were to perform a vaccination campaign at least once every 2 months.

Overall, from April 2017-April 2018, a total of 57,615 vaccinations were performed by NGOs and PHILOS in 15 and 10 camps, respectively: 21,031 against measles-mumps-rubella (MMR), 7,341 against diphtheria-tetanus-pertussis (DTP), 7,652 against poliomyelitis, 5,938 against pneumococcal disease, 7,179 against Haemophilus influenzae type b and 8,474 against hepatitis $B$.

Of the conducted vaccinations, 24,241 (42.1\%) were performed at camps on the mainland, 17,649 (30.6\%) at RICS, $14,941(25.9 \%)$ in the community and 784 $(1.4 \%)$ in safe zones.

\section{Assessment of vaccination coverage at mainland camps, April 2018}

An assessment to estimate the VC of refugee children living in camps on the mainland took place in April 2018. PHILOS personnel visited the mainland camps over 2 weeks and went door-to-door to identify children aged 0-14 years and their vaccination status, based on WHO booklets or other documents they had been provided after their arrival to Greece. Parents' statements regarding prior vaccinations were not taken into account.

The proportion of children 1-14 years of age that had been vaccinated against MMR and the proportion of 
TABLE 3

Number of vaccinated $^{a}$ refugee children at 25 mainland camps, by sex and nationality, Greece, April 2018 (n=3,786)

\begin{tabular}{|c|c|c|c|c|c|c|c|c|c|c|c|c|c|}
\hline \multirow{3}{*}{ Disease } & \multirow{3}{*}{$\begin{array}{l}\text { Vaccine } \\
\text { doses }^{b}\end{array}$} & \multicolumn{5}{|c|}{ Sex } & \multicolumn{7}{|c|}{ Nationality $^{d}$} \\
\hline & & \multicolumn{2}{|c|}{ Male } & \multicolumn{2}{|c|}{ Female } & \multirow{2}{*}{$p$ value ${ }^{e}$} & \multicolumn{2}{|c|}{ Syria } & \multicolumn{2}{|c|}{ Iraq } & \multicolumn{2}{|c|}{ Afghanistan } & \multirow{2}{*}{$p$ value $^{e}$} \\
\hline & & $\mathrm{n}$ & $\%$ & $\mathrm{n}$ & $\%$ & & $\mathrm{n}$ & $\%$ & $\mathrm{n}$ & $\%$ & $\mathrm{n}$ & $\%$ & \\
\hline \multirow{2}{*}{ MMR } & First & 1,528 & 82.0 & 1,299 & 82.1 & 0.975 & 1,166 & 80.1 & 811 & 79.8 & 608 & 88.0 & 0.001 \\
\hline & Second & 828 & 44.4 & 746 & 47.1 & 0.115 & 586 & 40.2 & 418 & 41.1 & 445 & 64.4 & $<0.001$ \\
\hline \multirow{2}{*}{ DTP } & First & 363 & 46.8 & 334 & 47.8 & 0.698 & 296 & 40.7 & 144 & 40.0 & 192 & 69.1 & $<0.001$ \\
\hline & Second & 192 & 24.8 & 177 & 25.4 & 0.796 & 142 & 19.5 & 66 & 18.3 & 128 & 46.0 & $<0.001$ \\
\hline \multirow{2}{*}{ Poliomyelitis } & First & 366 & 47.2 & 336 & 48.1 & 0.726 & 300 & 41.3 & 145 & 40.3 & 192 & 69.1 & $<0.001$ \\
\hline & Second & 193 & 24.9 & 177 & 25.4 & 0.841 & 143 & 19.7 & 66 & 18.3 & 128 & 46.0 & $<0.001$ \\
\hline \multirow{2}{*}{$\begin{array}{l}\text { Pneumococcal } \\
\text { disease }\end{array}$} & First & 394 & 50.8 & 355 & 50.9 & 0.994 & 336 & 46.2 & 153 & 42.5 & 194 & 69.8 & $<0.001$ \\
\hline & Second & 146 & 18.8 & 121 & 17.3 & 0.455 & 98 & 13.5 & 39 & 10.8 & 111 & 39.9 & $<0.001$ \\
\hline \multirow{2}{*}{$\begin{array}{l}\text { Haemophilus } \\
\text { influenzae type } b\end{array}$} & First & 363 & 46.8 & 332 & 47.6 & 0.781 & 294 & 40.4 & 144 & 40.0 & 192 & 69.1 & $<0.001$ \\
\hline & Second & 193 & 24.9 & 177 & 25.4 & 0.841 & 143 & 19.7 & 66 & 18.3 & 128 & 46.0 & $<0.001$ \\
\hline \multirow{2}{*}{ Hepatitis B } & First & 381 & 49.2 & 350 & 50.1 & 0.707 & 316 & 43.5 & 151 & 41.9 & 194 & 69.8 & $<0.001$ \\
\hline & Second & 193 & 24.9 & 179 & 25.6 & 0.744 & 145 & 19.9 & 66 & 18.3 & 128 & 46.0 & $<0.001$ \\
\hline
\end{tabular}

DTP: Diphtheria-tetanus-pertussis; MMR: measles-mumps-rubella.

${ }^{a}$ For the calculation of the vaccination coverage for MMR that refers to children 1-14 years of age $(n=3,501)$ the respective denominators were used: 1,863 of the children were male, 1,583 female, 1,456 were from Syria, 1,016 from Iraq and 691 from Afghanistan. Similarly, for the calculation of vaccination coverage for diphtheria-tetanus-pertussis, poliomyelitis, pneumococcal disease, Haemophilus influenzae type $b$ and hepatitis $B$ that refers to children $0-4$ years of age $(n=1,509)$, the following denominators were used: 775 children were male, 698 females 727 were from Syria, 360 from Iraq and 278 from Afghanistan.

${ }^{b}$ Coverage for more doses of the aforementioned vaccines (when applicable) was also recorded; however, the data was not presented here due to the low numbers of vaccinated children.

' Information regarding sex was missing for 64 records.

d Information regarding nationality was missing for five records. The other 375 children of 19 different nationalities are not included in the table.

e Pearson's chi-squared test $\mathrm{p}$ value.

children $0-4$ years of age that had been vaccinated against diphtheria-tetanus-pertussis, poliomyelitis, pneumococcal disease, Haemophilus influenzae type $\mathrm{b}$ and hepatitis B-by dose, sex and nationality-were calculated. The association between the VC for at least one dose of each vaccine and the size of the camp (1-99 hosted children, $\geq 100$ hosted children) was assessed.

In total, 3,786 children were recorded at the 25 camps on the mainland; 3,501 were 1-14 years of age and 1,509 were $0-4$ years of age. Of these, $78.9 \%$ had the WHO booklet $(2,572 / 3,261$ for whom this information was available). Of the 3,722 children for whom the information was available, 2,002 were male $(53.8 \%)$ and the mean age was 6 years (standard deviation $(\mathrm{SD} \pm$ 4.16). Overall, 22 different nationalities were recorded. Demographic data of children at the time of the survey are summarised in Table 1.

VC by disease is presented in Table 2. More than $80 \%$ of the children $1-14$ years of age $(2,843 / 3,501)$ had been vaccinated with the first dose of the MMR vaccine; however, for the second dose the coverage dropped to $45 \%(1,575 / 3,501)$. Coverage among children $0-4$ years of age was $150 \%$ for the first dose of all the other vaccines and below $25 \%$ for the second dose.

The number of vaccinated children by sex and nationality is presented in Table 3. Sex did not have a statistically significant association with VC. The proportion of children vaccinated at each camp had a statistically significant association with nationality. Children from Afghanistan had higher VC compared with Syrian and Iraqi children. Larger camps had higher $V C$ for at least one dose of MMR vaccine $(p=0.016)$ (Table 4). This difference appeared consistently for all other vaccines when looking at the point values, albeit without statistical significance.

\section{Lessons learnt and challenges}

Despite the positive outcome of PHILOS, a number of challenges were encountered while the programme was active.

\section{Availability of cultural mediators}

PHILOS and NGO personnel had to deal with an insufficient number of cultural mediators on site, a well-documented challenge in such settings $[6,7]$. Additionally, the camps' populations were constantly changing, with people moving from one camp to another or to community shelters. Eight camps closed in 2017 and two new ones opened, making vaccination status follow-up and planning of vaccination campaigns difficult.

To address this, vaccination campaigns were designed to be flexible and in several cases campaigns were postponed to assure the presence of cultural mediators. In other cases, campaigns had to be prolonged 
TABLE 4

Vaccination coverage $^{\mathrm{a}}$ of refugee children at 25 mainland camps, Greece, April $2018(\mathrm{n}=3,786)$

\begin{tabular}{|c|c|c|c|c|}
\hline \multirow[t]{2}{*}{ Disease } & \multirow[t]{2}{*}{ Vaccine doses } & $\begin{array}{l}\text { Camp size } \\
\text { (1-99 children) }\end{array}$ & $\begin{array}{c}\text { Camp size } \\
\text { ( } \geq 100 \text { children) }\end{array}$ & \multirow[t]{2}{*}{$p$ value } \\
\hline & & Mean $( \pm \mathrm{SD})$ & Mean $( \pm \mathrm{SD})$ & \\
\hline \multirow{2}{*}{ MMR } & No dose & $39.9( \pm 32.28)$ & $16.9( \pm 11.43)$ & \multirow{2}{*}{0.016} \\
\hline & At least one dose & $60.1( \pm 32.28)$ & $83.06( \pm 11.43)$ & \\
\hline \multirow{2}{*}{ DTPC } & No dose & $69.2( \pm 13.15)$ & $56.2( \pm 19.85)$ & \multirow{2}{*}{0.094} \\
\hline & At least one dose & $30.8( \pm 13.15)$ & $43.8( \pm 19.85)$ & \\
\hline \multirow{2}{*}{ Poliomyelitis } & No dose & $69.2( \pm 13.15)$ & $56.0( \pm 20.04)$ & \multirow{2}{*}{0.090} \\
\hline & At least one dose & $30.8( \pm 13.15)$ & $44.0( \pm 20.04)$ & \\
\hline \multirow{2}{*}{ Pneumococcal disease } & No dose & $56.1( \pm 29.40)$ & $56.4( \pm 19.67)$ & \multirow{2}{*}{0.977} \\
\hline & At least one dose & $43.9( \pm 29.40)$ & $43.6( \pm 19.67)$ & \\
\hline \multirow{2}{*}{ Haemophilus influenzae type b } & No dose & $69.7( \pm 13.00)$ & $56.2( \pm 19.84)$ & \multirow{2}{*}{0.081} \\
\hline & At least one dose & $30.3( \pm 13.00)$ & $43.8( \pm 19.84)$ & \\
\hline \multirow{2}{*}{ Hepatitis B } & No dose & $68.5( \pm 13.66)$ & $52.8( \pm 22.75)$ & \multirow{2}{*}{0.073} \\
\hline & At least one dose & $31.5( \pm 13.66)$ & $47.2( \pm 22.75)$ & \\
\hline
\end{tabular}

DTP: Diphtheria-tetanus-pertussis; MMR: measles-mumps-rubella; SD: standard deviation.

${ }^{a}$ Vaccination coverage against MMR for children 1-14 years of age $(n=3,501)$ and vaccination coverage against diphtheria-tetanus-pertussis, poliomyelitis, pneumococcal disease, Haemophilus influenzae type b and hepatitis B for children $0-4$ years of age ( $n=1,509$ ), by camp size (1-99 children and $\geq 100$ ).

b Student's t-test p-value.

in order to cover newcomers or unexpected needs. All available human resources that could support mediation were utilised. In addition to NGO and PHILOS personnel, volunteers from the community and in some cases members of the camps' populations also supported vaccination efforts.

\section{Limitations of recording VC}

The results of the survey in April 2018 were useful, as constant monitoring of VC in the camps via a specially designed vaccination registry was not possible. However, the estimated coverage only accounts for the 3,786 children recorded as living in the camps in April 2018 and cannot be extrapolated to the population living in RICs or in the community, or to those who occupied the camps in the following months. RICs were not included in the study because the increased workload for the medical staff and the continuous arrival of refugees made door-to-door surveying impossible.

\section{Insufficient vaccination coverage remained for a number of diseases}

As at April 2018, VC was high for the first dose of the vaccine against MMR, but was far from optimal for the second dose, as well as for the first and second dose against pneumococcal disease, hepatitis $B$, poliomyelitis, diphtheria-tetanus-pertussis and Haemophilus influenzae type b. Therefore, mass vaccination campaigns were still needed. During the months following the assessment, new campaigns were designed, giving priority to the camps with the lowest VC.

The use of a combination vaccine that protects against diphtheria, tetanus, pertussis, poliomyelitis, hepatitis
$B$ and infection with Haemophilus influenzae type B bacteria in most of the vaccination campaigns explains the similar VC for all six diseases.

\section{Differing vaccination coverage by nationalities and camp size}

The difference in VC by nationality may be attributed to the quicker turnover of the Syrian population at camps, as they had more straightforward access to the asylum processes. Syrian children represented in the study may have missed prior vaccination campaigns if they had recently entered the camps. However, this is just a hypothesis, as the dates of arrival at the camps were not recorded.

The higher vaccination coverage at larger camps may be explained by the fact that vaccination campaigns might have been more organised, frequent and effective compared with those at smaller ones.

\section{Increased refugee childhood population in the community}

Vaccination activities for refugee children living in the community at hotels, hostels or private houses were designed for the first time; however, the estimated number of unvaccinated children in the community was beyond the purposes of this study. By the end of April 2018, the number of refugees living in the community had increased to more than $20,000,48 \%$ of whom were children [8]. As the number of refugee children in the community steadily became greater than the number of children hosted at the mainland camps, priority had to be given to this population. Therefore, vaccination interventions began to be implemented in 
the community, not only at the camps, as was done previously. During this period, the PHILOS programme focused on covering vaccination gaps, with the support of health regions as previously described, and guiding families living outside camps to acquire national health security numbers that would allow for vaccinations based on the NCIP, free of charge.

\section{Conclusion}

Vaccination of refugee children is a priority for host countries; however, several studies have documented that refugees have low immunisation rates and encounter essential barriers in accessing routine healthcare services.

In 2017, the PHILOS programme took over the coordination of refugee children's vaccinations in Greece. PHILOS set standard operating procedures for identifying vaccination needs at camps and RICs, performing information campaigns with the support of cultural mediators and promoting the use of a singular booklet for documenting vaccination history for all children. PHILOS' activities showed that the implementation of a coordinated approach to vaccinations in such a complex situation and setting is feasible and provided a useful experience of cooperation between the HCDCP, $\mathrm{MoH}$, regional public health authorities, international organisations, NGOs and other stakeholders in organising vaccination campaigns. Overall, the programme demonstrated progress in the coordination of vaccinations for refugee children in Greece. Vaccination of all refugee children upon arrival and enhancement of continued access to healthcare should be future public health priorities.

\section{Acknowledgements}

We would like to acknowledge the support and the substantial contributions of Red Cross, Praksis, Doctors Without Borders (MSF) and Doctors of the World (MdM) to the vaccination of the population staying at the accommodation camps for refugees/migrants in mainland Greece. Also, we would like to thank the National Centre for Social Solidarity and the UNHCR for their support and cooperation. Furthermore, we would like to thank the programme 'Health for All' and the personnel of the PHILOS programme and the HCDCP that actively participated in the activities described in this report.

Naturally, we would also like to thank UNICEF for donating 62,200 doses of three vaccines $(50,000 \mathrm{MMR}, 11,000$ PCV and 1,200 PCG) to the Ministry of Health in September 2016, in order to cover the vaccination needs of the migrant/ refugee population living in Greece. Also, we would like to acknowledge the members of the previous and current working group for the coordination of vaccinations of refugees in Greece: Theodora Stavrou, Panagiotis Panagiotopoulos, Apostolos Veizis, Pantelia Goura, Dionisios Sgouras, Eirini Tagiadou, Dimitrios Tsoukalas, Ioannis Spyridis, Katerina Tsekou, Chrysovalantou Kefaloudi and Tzoyfi Eleonora.

Funding: The 'European Programme PHILOS - Emergency health response to migrant/refugee crisis' is a programme of the Greek Ministry of Health, implemented by the Hellenic Centre for Disease Control and Prevention (HCDCP) and funded by the Asylum, Migration and Integration Fund (AMIF) of the EU's DG Migration and Home Affairs.
Conflict of interest

None declared.

Authors' contributions

KM conceived of the study and its design, led the study organization and coordination, contributed to the interpretation of the data, as well as the manuscript's first draft and revisions. CS contributed to the collection of the data, to the analysis of the results and drafting the manuscript. ESP performed the statistical analysis, contributed to the background and methodology and reviewed the manuscript. AS participated in the design of the work and coordination, and reviewed the manuscript. IDP, TG, CB and AT contributed to the critical revision of the manuscript. All authors discussed the results and approved the final manuscript.

\section{References}

1. The UN Refugee Agency (UNHCR). Mediterranean situation, Greece. Geneva: UNHCR. [Accessed 30 Dec 2018]. Available from: https://data2.unhcr.org/en/situations/mediterranean/ location/5179

2. Danish Refugee Council (DRC). Closing borders, shifting routes: summary of regional migration trends Middle East. DRC Middle East and North Africa (MENA). Copenhagen: DRC; 2016. [Accessed 30 Dec 2018]. Available from: https://reliefweb. int/sites/reliefweb.int/files/resources/DRC\%20-\%20ME\%20 Migration\%20Trends\%20May.pdf

3. Ministry of Health (MoH). Vaccinations of refugees, asylum seekers and migrants. Athens: $\mathrm{MoH} ; 2016$. [Accessed 30 Dec 2018]. Available from: http://philosgreece.eu/images/ MyMedia/pdfs/informative/vaccination2.pdf

4. National School of Public Health. Vaccination of refugees/ migrants in accommodation centres. Athens: NSPH; 2017. [Accessed: 15 Jan 2018]. Available from: https://government. gov.gr/wp-content/uploads/2017/02/Ekthesi-emvoliasmosprosfygon-2017-02.pdf

5. National and Kapodistrian University of Athens. Health for All project. Athens: UoA; 2017. [Accessed: 15 Jan 2018]. Available from: http://www.ygeiagiaolous.org/?lang=en\#

6. Riccardo F, Suk JE, Espinosa L, Bella A, Giambi C, Del Manso $M$, et al. Key Dimensions for the Prevention and Control of Communicable Diseases in Institutional Settings: A Scoping Review to Guide the Development of a Tool to Strengthen Preparedness at Migrant Holding Centres in the EU/EEA. Int J Environ Res Public Health. 2018;15(6):E1120. https://doi. org/10.3390/ijerph15061120 PMID: 29849000

7. World Health Organization (WHO). Public health aspects of migrant health: a review of the evidence on health status for refugees and asylum seekers in the European region Copenhagen: WHO Regional Office for Europe; 2015. Available from: http://www.euro.who.int/__data/assets/pdf_ file/0004/289246/WHO-HEN-Report-A5-2-Refugees_FINAL. pdf?ua $=1$

8. The UN Refugee Agency (UNHCR). Weekly accommodation update. Geneva: UNHCR; 2018. [Accessed: 15 Jan 2018] Available from: https://data2.unhcr.org/es/documents/ download/63251

\section{License, supplementary material and copyright}

This is an open-access article distributed under the terms of the Creative Commons Attribution (CC BY 4.0) Licence. You may share and adapt the material, but must give appropriate credit to the source, provide a link to the licence and indicate if changes were made.

Any supplementary material referenced in the article can be found in the online version.

This article is copyright of the authors or their affiliated institutions, 2019. 